\title{
A Cross-Sectional Study On Caregivers' Knowledge, Attitudes and Practices about the Routine Immunisation Program in Tshwane Sub-District 2, Gauteng, South Africa: 2015
}

\author{
Makgomo R Mphaka ${ }^{1,2,3^{*}}$, Mpho Moshime ${ }^{3}$, Carl Reddy ${ }^{1}$
}

${ }^{1}$ South African Field Epidemiology Training Programme, National Institute of Communicable Diseases, South Africa

${ }^{2}$ School of Public Health and Health Systems, University of Pretoria, South Africa

${ }^{3}$ Expanded Programme on Immunisation, Communicable Disease Control, Outbreak Response, Department of Health, South Africa

"Corresponding Author: Makgomo R Mphaka, Department of Health Sciences, School of Public Health and Health Systems, University of Pretoria, South Africa, E-mail: makgomom@yahoo.com

Received: 23 November 2018; Accepted: 12 December 2018; Published: 28 December 2018

\begin{abstract}
Introduction: Despite childhood immunisation services being free in South Africa, Tshwane sub-district 2 continues to have the lowest vaccine coverage rate of all the Tshwane sub-districts in Gauteng province which is below the $90 \%$ national target. For measles, the immunisation coverage target is $95 \%$ and $90 \%$ for other antigens. To understand the factors for low coverage, a caregivers' knowledge, attitudes and practices (KAP) study regarding the routine immunisation programme was done.
\end{abstract}

Methods: A cross sectional survey was conducted among caregivers of children $<5$ years old attending 10 of the 12 clinics in sub-district 2 for any health reason from June to August 2015. An interviewer-administered questionnaire was used and immunisation cards were reviewed. Of 23 questions asked, 18 assessed knowledge, 3 attitudes and 2 practices. Descriptive statistics were used to describe the data using STATA version 13 and Microsoft Excel. 
Results: A total of 326 caregivers were enrolled. Mean caregiver age [standard deviation (SD)] was 29.1 (9.61) years. Although 29\% (94/326) of the caregivers knew at least three vaccine preventable diseases (VPDs), 13\% did not know any. Approximately one third of caregivers, $(114 / 326,35 \%)$ could list at least two VPDs, with polio (70.3\%) and measles (57.7\%) being mentioned most often. Of the 318 cards reviewed, $82 \%$ of children were fully immunised. Mean (SD) score for knowledge was 5.4 (2.7), out of 18; while for attitudes and practices it was 4.4 (1.1), out of 5 .

Conclusion: Low knowledge, even among caregivers of infants who were fully immunised, but positive attitudes regarding immunisation were found among caregivers in Tshwane sub-district 2 . To attain the $95 \%$ immunisation coverage target, health care providers should identify caregivers with infants that are not fully immunised to understand what modifiable risk factors are associated with low immunisation coverage and ways to intervene.

Keywords: Tshwane district; Routine immunization; Caregivers; Vaccine preventable diseases

Abbreviations: BCG-Bacilles Calmette Guerine; DTaP-IPV/Hib-Diphtheria, Tetanus, Acellular Pertussis, Inactivated Polio Vaccine, Haemophilus Influenza Type B combined; HepB-Hepatitis B; OPV-Oral Polio Vaccine; PCV-Pneumococcal Conjugate Vaccine; RV-Rotavirus Vaccine; Td-Tetanus and reduced strength of Diphtheria Vaccine

\section{Introduction}

Immunisation is one of the most cost-effective public health tools for combating and eliminating infectious diseases $[1,2]$. It has led to a decline in morbidity and mortality associated with vaccine preventable diseases (VPDs) since the implementation of the immunisation schedule recommended by the World Health Organization (WHO) [2]. Immunisation coverage rate is considered to be a surrogate measure of protection [3]. The WHO estimates that 2.5 million children $<5$ years die from VPDs each year [4, 5]. Children should receive all their immunisations within recommended intervals and at the appropriate age in order to have maximal protection against VPDs [6]. Incomplete immunisation is a significant public health problem as low coverage rates can affect herd immunity and therefore pose a threat for outbreaks [7]. Caregivers play an important role in the immunisation of children [8]. Their compliance with immunisation schedules leads to full immunisation of children, thus preventing VPDs in children [2].

Immunisation coverage rates monitor the performance of immunisation services internationally, nationally and locally and guide decision making and planning of disease control initiatives [9]. The Expanded Programme on Immunisation-South Africa (EPI-SA) aims to prevent mortality and morbidity in children [10]. There are currently 10 antigens in the South African immunisation schedule administered to children aged 0-12 years. Catch up vaccination can be done up to the age of 15 years. A child is said to be fully immunised if he/she had received all doses of vaccines for his/her age according to the EPI-SA schedule. In South Africa, immunisation services are 
available to all children and women at public health facilities for free on a daily basis, although there are clinics that do vaccinations on certain days of the week only. At the national level, immunisation coverage rate targets vary based on the communicability of the disease. It is set at a target of $95 \%$ for measles and $90 \%$ for all other vaccine antigens. Despite free immunisation services in South Africa, the immunisation coverage rates are still below the national target. Gauteng is one of the nine provinces in South Africa and has five districts. Of these, Tshwane has seven sub-districts, all of which affect the province's performance towards achieving the national target. In Tshwane sub-district 2 there was low immunisation coverage for all antigens (Table 1).

\begin{tabular}{|c|c|c|c|c|c|c|c|c|c|}
\hline Vaccinations & Apr & May & Jun & Jul & Aug & Sep & Oct & Nov & Dec \\
\hline BCG dose & 94.2 & 116.0 & 110.5 & 88.6 & 112.7 & 104.4 & 93.2 & 28.8 & 102.8 \\
\hline DTaP-IPV/Hib $1^{\text {st }}$ dose & 71.2 & 83.5 & 69.5 & 80.0 & 71.1 & 82.4 & 82.1 & 59.6 & 68.2 \\
\hline DTaP-IPV/Hib $2^{\text {nd }}$ dose & 72.0 & 75.9 & 74.4 & 71.9 & 66.5 & 78.6 & 76.8 & 68.7 & 66.8 \\
\hline DTaP-IPV/Hib $3^{\text {rd }}$ dose & 57.5 & 95.6 & 69.0 & 83.8 & 72.4 & - & 74.8 & 62.3 & 72.4 \\
\hline DTaP-IPV/Hib $4^{\text {th }}$ dose & 41.8 & 45.5 & 66.2 & 51.1 & 49.7 & 57.4 & 53.5 & 46.6 & 39.5 \\
\hline HepB $1^{\text {st }}$ dose & 74.8 & 88.6 & 74.9 & 75.2 & 66.9 & 79.4 & 81.0 & 63.1 & 68.5 \\
\hline HepB $3^{\text {rd }}$ dose & 55.9 & 83.2 & 77.5 & 70.3 & 68.1 & 78.1 & 70.9 & 69.5 & 70.8 \\
\hline Measles $1^{\text {st }}$ dose & 56.3 & 52.8 & 81.8 & 71.7 & 62.0 & 77.6 & 77.5 & 68.4 & 63.8 \\
\hline Measles $2^{\text {nd }}$ dose & 44.7 & 32.0 & 65.6 & 53.0 & 44.5 & 57.4 & 53.0 & 48.7 & 40.0 \\
\hline OPV $1^{\text {st }}$ dose & 73.0 & 81.3 & 66.1 & 78.7 & 68.1 & 85.1 & 82.7 & 59.5 & 67.3 \\
\hline PCV $1^{\text {st }}$ dose & 67.4 & 82.1 & 73.3 & 74.9 & 70.6 & 80.8 & 75.4 & 58.8 & 68.1 \\
\hline PCV $2^{\text {nd }}$ dose & 53.7 & 83.5 & 68.9 & 78.4 & 69.8 & 68.5 & 72.4 & 65.7 & 69.8 \\
\hline PCV $3^{\text {rd }}$ dose & 51.0 & 58.0 & 77.8 & 66.9 & 59.1 & 66.8 & 70.3 & 65.0 & 59.8 \\
\hline $\mathrm{RV} 1^{\text {st }}$ dose & 71.2 & 86.2 & 74.8 & 75.1 & 71.6 & 85.7 & 78.6 & 59.8 & 67.6 \\
\hline $\mathrm{RV} 2^{\text {nd }}$ dose & 54.7 & 86.4 & 77.9 & 79.7 & 66.0 & 81.0 & 68.9 & 66.6 & 69.7 \\
\hline Td dose 6 years & 22.7 & 27.4 & 33.2 & 26.8 & 30.1 & 23.2 & 19.0 & 27.1 & 19.6 \\
\hline Td dose 12 years & 6.6 & 6.4 & 11.1 & 10.0 & 24.1 & 13.0 & 8.5 & 9.5 & 9.7 \\
\hline
\end{tabular}

Table 1: Immunization coverage rates for all antigens in Tshwane Sub-district 2, Gauteng Province, South Africa, April-December 2013.

Tshwane's sub-district 2 had the lowest immunisation coverage relative to the other six sub-districts in Tshwane district. However, the cause of the low immunisation coverage rates is unknown Data generated from this study can be used for strengthening immunisation services in this sub-district and other sub-districts in Tshwane that do not meet the set target. This study aimed to explore knowledge, attitudes and practices about routine immunisation among caregivers of children $<5$ years in Tshwane sub-district 2 and to explore the difference between caregivers of fully vaccinated children and those not fully vaccinated. 


\section{Methods}

\subsection{Study design and site}

A cross sectional survey was conducted among the eligible caregivers of $<5$ children from June 2015 to August 2015.

\subsection{Study site and study population}

The study was conducted in 10 of the 12 public health facilities in Tshwane sub-district 2 that provide primary health care services. Eligibility criteria included caregivers whose children were $<5$ and had been residing in subdistrict 2 for more than 6 months, who attended the clinic for immunisation services and/or other services and gave written consent.

\subsection{Sampling and sample size}

Assuming a 5\% level of significance, 95\% confidence interval, precision of 5.5\% confidence interval width, and $100 \%$ response rate, the minimum sample size required was 314 calculated using Epi Info 7 software. The total population of children <5 years in Tshwane sub-district 2 was estimated to be 33,209 using Statistics of South Africa (STATSSA) estimates from 2013. Caregivers were conveniently selected by consecutively enrolling all caregivers who visited the clinic on the day of the researcher's visit.

\subsection{Data collection}

We administered an interviewer-administered questionnaire that consisted of twenty three questions: eighteen assessed knowledge, three attitudes and two practices. Vaccination record, Road to Health Cards/booklets (RTHC/B) were reviewed to check the percentage of children fully immunised for their age, according to South Africa EPI guidelines.

\subsection{Data analysis}

Data were summarized using frequency distribution tables related to knowledge, attitudes and practices of caregivers. Microsoft Excel 2013 was used to generate the frequency distribution tables and bar charts. Data were analysed using Microsoft Excel 2013 and STATA 13. For the purpose of scoring participants regarding their knowledge, attitudes and practices, responses for each question were assigned a score of ' 1 ' for a correct/positive response and a score of ' 0 ' for a wrong/ negative response. The scores were summed up for each participant and the mean (SD) scores were calculated for the whole sample. The scores of fully immunised and not fully immunised were compared to determine if there was any statistically significant difference between the two groups.

\subsection{Ethical considerations}

Caregivers provided written consent if they were willing to participate in the study. Participants were given study identification numbers and no personal identifiers were used on the questionnaires. Ethical clearance was obtained 
from the University of Pretoria ethics committee. Permission to conduct research in Tshwane was obtained from Tshwane Research Committee, and facility managers of participating clinics in Tshwane sub-district 2.

\section{Results}

\subsection{Sociodemographic factors}

We enrolled 326 caregivers of $<5$ children. The mean (SD) age of caregivers was 29.1 (9.6) years, 94.7\% (317/326) were females, $85.3 \%$ (262/326) were single, $87.6 \%$ (263/326) were unemployed, 764\% (249/326) had an income of less than 500 South African Rands ( US\$50) per month and 163 (74.8\%) had a high school education. Of all caregivers, $92 \%(300 / 326)$ were parents of children $<5$ (Table 2).

\begin{tabular}{|c|c|c|}
\hline Sociodemographic characteristics & Frequency $(n=326)$ & $(\%)$ \\
\hline \multicolumn{3}{|l|}{ Age groups } \\
\hline$<20$ & 29 & 8.9 \\
\hline $20-29$ & 167 & 51.2 \\
\hline $30-39$ & 105 & 32.2 \\
\hline $40-49$ & 10 & 3.1 \\
\hline $50+$ & 15 & 4.6 \\
\hline \multicolumn{3}{|l|}{ Gender } \\
\hline Females & 317 & 97.2 \\
\hline \multicolumn{3}{|l|}{ Relationship to child } \\
\hline Parent & 300 & 92.0 \\
\hline Grandparent & 16 & 5.0 \\
\hline Aunt & 8 & 2.5 \\
\hline Sister & 0 & 0 \\
\hline Brother & 1 & 0.3 \\
\hline Uncle & 1 & 0.3 \\
\hline \multicolumn{3}{|l|}{ Marital status } \\
\hline Single & 262 & 85.3 \\
\hline Married & 57 & 13.3 \\
\hline Divorced & 3 & 0.9 \\
\hline Widowed & 4 & 0.5 \\
\hline \multicolumn{3}{|l|}{ Employment status } \\
\hline Employed & 55 & 10.1 \\
\hline Unemployed & 263 & 87.6 \\
\hline Pensioner & 8 & 2.3 \\
\hline
\end{tabular}




\begin{tabular}{|l|l|l|}
\hline $0-500$ & 255 & 78.2 \\
\hline $501-999$ & 7 & 2.2 \\
\hline $1000-1999$ & 26 & 8.0 \\
\hline $2000-2999$ & 20 & 6.1 \\
\hline Above 3000 & 18 & 5.5 \\
\hline Educational status & 3 & 0.9 \\
\hline No formal education & 37 & 8.3 \\
\hline Primary school & 27 & 73.9 \\
\hline High school & 245 & 15.6 \\
\hline Tertiary education & 21 & \\
\hline
\end{tabular}

Table 2: Socio-demographic characteristics of caregivers of children <5years in Tshwane sub-district 2, 2015.

\subsection{Immunisation status of children}

We reviewed 98\% (318/326) of immunisation cards. Eight caregivers said their children were fully immunised, but did not have immunisation cards in their possession. The lowest immunisation coverage was found among children $>18$ months (Table 3 ).

\begin{tabular}{|l|l|l|l|l|l|}
\hline \multirow{2}{*}{ Age } & \multicolumn{2}{|l|}{ Immunisation status } & \%immunised & Total \\
\cline { 2 - 5 } & Complete & Incomplete & Unimmunised & & \\
\hline$<6$ weeks & 12 & 0 & 1 & $92 \%$ & $13(4.0 \%)$ \\
\hline 6weeks-10weeks & 40 & 7 & 0 & $85 \%$ & $47(14.4 \%)$ \\
\hline 11 weeks-14weeks & 20 & 6 & 0 & $77 \%$ & $26(8.0 \%)$ \\
\hline 15 weeks-9months & 95 & 4 & 1 & $95 \%$ & $100(30.7 \%)$ \\
\hline 10 months-18months & 47 & 10 & 0 & $81 \%$ & $58(17.8 \%)$ \\
\hline$>18$ months-60 months & 52 & 30 & 1 & $63 \%$ & $82(25.2 \%)$ \\
\hline Total & $\mathbf{2 6 6}$ & $\mathbf{5 7}$ & $\mathbf{3}$ & & $\mathbf{3 2 6}(\mathbf{1 0 0 \%})$ \\
\hline
\end{tabular}

Table 3: Immunisation status of children <5 years (n=326) according to EPI-SA guidelines, Tshwane district: 2015.

3.3 Knowledge, attitudes and practices regarding immunisations

The mean (SD) score for knowledge, attitudes and practices was $9.8 \pm 3.2$, out of 23 (Table 4). The mean (SD) score for attitudes and practices was 4.4 (1.1), out of 5. There was no significant difference in the mean score for knowledge between caregivers of fully immunised versus not fully immunised children (9.2 versus 8.9, $\mathrm{p}=0.449)$. 


\begin{tabular}{|l|l|l|}
\hline Attribute & Mean \pm SD & Total number of questions \\
\hline Scores for not fully immunised group & $8.9 \pm 2.97$ & 18 \\
\hline Knowledge score & $4.8 \pm 2.38$ & 23 \\
\hline Overall knowledge, Attitudes and Practices & $9.2 \pm 2.73$ & 18 \\
\hline Scores for fully immunised group & $4.8 \pm 2.32$ & 23 \\
\hline Knowledge score & \multicolumn{2}{|l|}{} \\
\hline Overall knowledge, Attitudes and Practices & $5.4 \pm 2.7$ & 18 \\
\hline Overall scores for both groups & $4.4 \pm 1.1$ & 5 \\
\hline Overall knowledge score & $\mathbf{2 3}$ \\
\hline Overall score for Attitude and practices & $\mathbf{9 . 8} \pm \mathbf{3 . 2}$ \\
\hline Overall Knowledge, Attitude and practices score &
\end{tabular}

Table 4: Mean scores for knowledge, attitude and practices among caregivers of children <5years, Tshwane subdistrict 2: 2015.

Of all caregivers, 13\% (43/326) did not know any VPDs Measles and polio were mentioned by 33\% (108/326) of the caregivers relative to other VPDs (Figure 1).

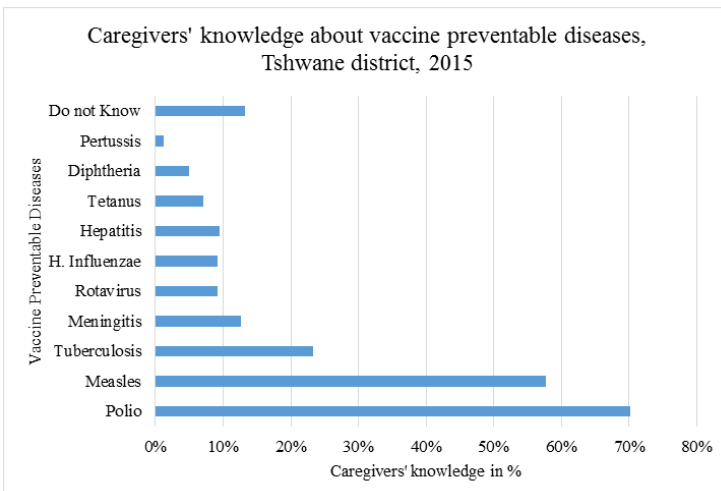

Figure 1: Knowledge of caregivers regarding vaccine preventable diseases in Tshwane sub-district 2, Gauteng Province, 2015.

Diabetes Mellitus 4\% (14/326), worm infestation 0.3\% (1/326), leprosy 0.3\% (1/326), chicken pox 0.6\% (2/326), malaria $0.6 \%$ (2/326) and HIV/AIDS 7\% (23/326) were also mentioned as VPDs. Caregivers were considered to have adequate knowledge if they mentioned three or more VPD's. Of all caregivers, 26\% (94/326) demonstrated adequate knowledge regarding VPD's. Regarding side effects of vaccines, swelling was mentioned by $45 \%$ (147/326) of caregivers (Figure 2). 


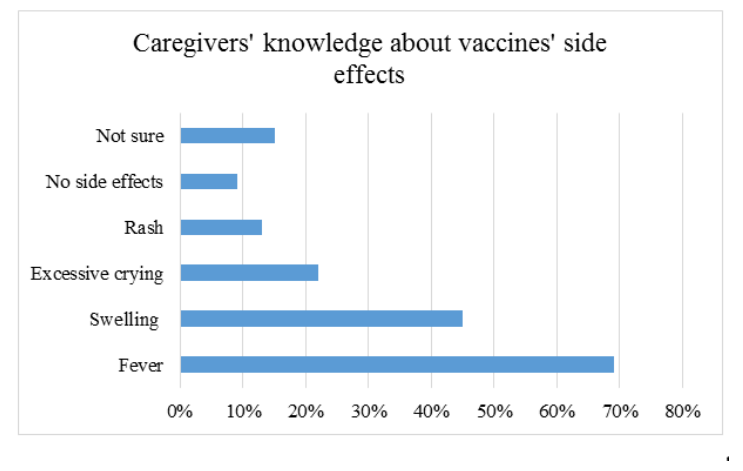

Figure 2: Caregivers' knowledge about vaccines' side effects, Tshwane sub-district 2, 2015.

Fever was mentioned by $69.3 \%$ (226/326) of caregivers as a contraindication to immunisation. Overall knowledge that immunization prevents disease was demonstrated by $95 \%$ (311/326) of the caregivers (Figure 3). Additionally, 98\% (319/326) were confident that immunisations were safe for their children (Figure 4).

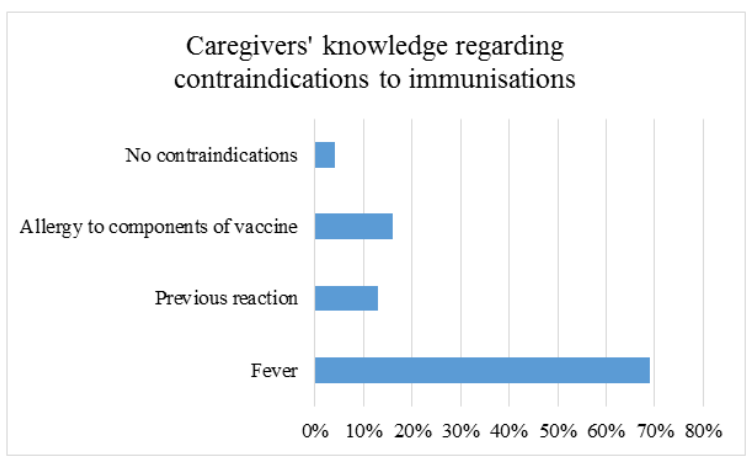

Figure 3: Caregivers' knowledge about contraindications to immunisations, Tshwane sub-district 2, 2015.

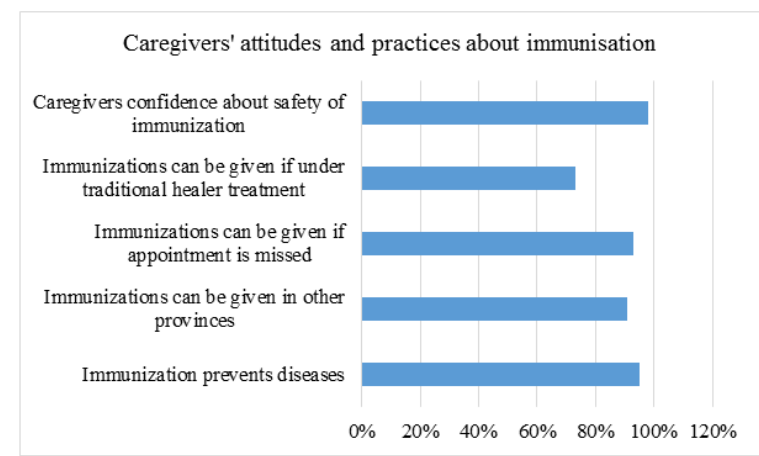

Figure 4: Caregivers' attitudes and practices in Tshwane sub-district 2, 2015.

\subsection{Health system factors}

Of the 326 caregivers, 90\% (295/326) had a return date written on their RTHC. Of those who were not given a written return date, some reported that it was given verbally. Immunisation services at facilities were noted by $81 \%$ (264/326) of caregivers to be friendly and accessible. It was reported by $96 \%$ (318/326) of caregivers that they were 
never turned away from the facility without being helped. Of those turned away, various reasons were given; late for immunisation $0.9 \%$ (3/326); missed appointment date $0.9 \%$ (3/326); or no vaccines at the clinic $0.6 \%(2 / 326)$.

\section{Discussion}

This study aimed to explore knowledge, attitudes and practices about routine immunisation among caregivers of children $<5$ in Tshwane sub-district 2 and to explore the difference between caregivers of fully vaccinated children and those not fully vaccinated. The knowledge of VPDs was low in both groups of caregivers, those whose children were fully vaccinated and those whose children were not fully vaccinated. However, their attitudes towards immunisation were generally positive. There were no differences between the scores in knowledge, attitude and practices among the fully immunised and not fully immunised groups.

Overall, most of the caregivers knew that immunisations prevent diseases and that vaccines were safe for their children but they could not mention the different vaccine preventable diseases and side effects. This is similar to the findings of the study conducted in Nigeria, India and in the Democratic Republic of Congo [11-13]. However, the caregivers had positive attitudes towards immunisations. In our study, measles and polio were mentioned by a one third of the caregivers as a VPD. Poor knowledge regarding immunisations did not appear to have contributed to low coverage rates. This is in contrast to studies conducted in Nigeria and Pakistan that noted that vaccination coverage was significantly correlated with caregiver knowledge on immunization [14, 15]. This suggests that caregiver knowledge is not the sole factor that improves the likelihood of an infant being fully vaccinated. Regarding practices, the immunisation status of children differed across different age groups. The majority of children $<18$ months were fully immunised. Those not fully immunised in this age group cited health system factors, including stock outs of vaccines, negative attitudes of staff, and long waiting times. A study in North West Province, South Africa identified that low immunisation uptake was associated with low income status, large families, migrant status, education level of mothers and certain cultural beliefs [1]. In Nigeria, causes of low coverage were found to be inadequate vaccine supply in facilities and lack of knowledge about immunisation benefits and schedules [16]. The lowest percentage of children fully immunised according to their age was among those $>18$ months. This is similar to other studies that have shown that immunisation coverage declines with older age [6]. The limitations of the study included a non-representative sample: 10 out of 12 clinics in Tshwane sub-district 2 gave permission to conduct research. We used convenience sampling: interviewing those caregivers who were at the clinics during the researchers visit. These two limitations compromised the generalizability of our findings to the whole country.

\section{Conclusion}

Overall, the knowledge of caregivers regarding routine immunisation was poor. However, their attitudes and practices were generally positive. To improve the coverage, health care providers should identify caregivers with infants that are not fully immunised to explore what modifiable risk factors are associated with non vaccination and identify intervention measures. Health promotion messages should focus on the importance of immunisations, 
VPD's, side effects and contraindications and how to manage them. All Road to Health booklets/cards should be checked when children $<5$ attend the clinics for any reason.

\section{Authors' contributions}

MM: Contributed to the design of the study, supervised field operations, data analysis and interpretation as well as manuscript writing. MM: Conception of the study. CR: supervised data analysis and contributed to critical review of the manuscript. All authors reviewed and edited subsequent manuscript drafts. All authors have seen and approved the final version of the manuscript.

\section{Competing interests}

The authors declare that they have no competing interests.

\section{Acknowledgements}

We gratefully acknowledge funding from School of Health Systems and Public Health Research Committee (SHSPH RESCOM), University of Pretoria and Ms Manchaba Gloria Masenya for the contribution she has made during data collection and thank all the caregivers who participated in the study. We are grateful to Dorothy $\mathrm{L}$. Southern for her input and guidance on scientific writing and for the critical review of this manuscript.

\section{References}

1. Sehume KL. Childhood immunization in Mmakaunyane village in the North West Province of South Africa. University of Limpopo (Medunsa Campus) (2011).

2. Falagas ME, Zarkadoulia E. Factors associated with suboptimal compliance to vaccinations in children in developed countries: A systematic review. Curr Med Res Opin 24 (2008): 1719-1741.

3. Murhekar MV, Bitragunta S, Hutin Y, et al. Immunization coverage and immunity to diphtheria and tetanus among children in Hyderabad, India. Journal of infection 58 (2009): 191-196.

4. Tsuda Y, Watanabe M, Tanimoto Y, et al. The Current Situation of Voluntary Vaccination and the Factors Influencing Its Coverage Among Children in Takatsuki, Japan: Focus on Hib and Pneumococcal Vaccines. Asia Pac J Public Health 27 (2013): 1409-1420.

5. Sensarma P, Bhandari S, Kutty VR. Barriers to Immunization among Children of HIV-Infected Mothers in Kolkata, India: A Qualitative Study. Asia Pac J Public Health 27 (2013): 1362-1371.

6. Schwarz NG, Gysels M, Pell C, et al. Reasons for non-adherence to vaccination at mother and child care clinics (MCCs) in Lambarene, Gabon. Vaccine 27 (2009): 5371-5375.

7. Hu Y, Chen E, Li Q, et al. Immunization Coverage and Its Determinants among Children Born in 20082009 by Questionnaire Survey in Zhejiang, China. Asia Pac J Public Health 27 (2011): 1132-1143.

8. Abdulraheem I, Onajole A, Jimoh A, et al. Reasons for incomplete vaccination and factors for missed opportunities among rural Nigerian children. Journal of Public Health and Epidemiology 3 (2011): 194203. 
9. World Health Organization. WHO vaccine-preventable diseases: monitoring system: 2009 global summary (2009).

10. Vaccinators Manual, Immunization that works: Expanded Program on Immunization (EPI-SA) (2012).

11. EN Ekure CE, M Mukhtar-Yola, MR Balogun, et al. Community knowledge, attitude and practice of childhood immunization in Southwest Nigeria: Data from a Paediatric Association of Nigeria town hall meeting. Nigerian Journal of Pediatrics 40 (2013): 106-111.

12. Mapatano MA, Kayembe K, Piripiri L, et al. Immunization-related knowledge, attitudes and practices of mothers in Kinshasa, Democratic Republic of the Congo: Original research. South African Family Practice 50 (2008): 61.

13. Angadi M, Jose AP, Udgiri R, et al. A study of knowledge, attitude and practices on immunization of children in urban slums of bijapur city, karnataka, India. J Clin Diag Research 7 (2013): 2803-2806.

14. Odusanya OO, Alufohai EF, Meurice FP, et al. Determinants of vaccination coverage in rural Nigeria. BMC Public health 8 (2008): 1.

15. Owais A, Hanif B, Siddiqui AR, et al. Does improving maternal knowledge of vaccines impact infant immunization rates? A community-based randomized-controlled trial in Karachi, Pakistan. BMC public health 11 (2011).

16. Babalola S. Maternal reasons for non-immunization and partial immunization in northern Nigeria. J Paediatr Child Health 47 (2011): 276-281.

Citation: Makgomo R Mphaka, Mpho Moshime, Carl Reddy. A Cross-Sectional Study On Caregivers' Knowledge, Attitudes and Practices about the Routine Immunisation Program in Tshwane Sub-District 2, Gauteng, South Africa: 2015. Journal of Environmental Science and Public Health 2 (2018): 221-231.

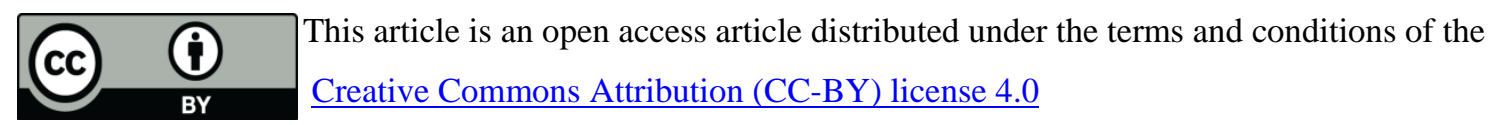

